\title{
The temporal architecture of central information processing: Evidence for a tentative time-quantum model
}

\section{H.-G. Geißler}

Sektion Psychologie, Karl-Marx-Universität Leipzig, Tieckstrasse 2, DDR-7030 Leipzig, German Democratic Republic Psychological Research (1987) 49:99-106

1. Page 99, right column, second line from the bottom should have read : " $106.1 \mathrm{~ms}$ " instead of " $0.1061 \mathrm{ms."}$

2. Page 104, left column, 3rd paragraph, line 5 should have read: " $I_{6}=1728,3456$ " instead of " $I_{6}=1628,3456 . "$

3. Page 105 , left column, 7 th paragraph, line 6 should have read: " $4 \cdot 16^{2}$ "instead of " $4=16^{2}$." 